\title{
DEMOGRAPHIC SITUATION IN RURAL AREAS OF REPUBLIC OF BULGARIA IN 21 CENTURY
}

DOI: http://dx.doi.org/10.18509/GBP.2015.26

UDC: 314:911.272(497.2),,21vek“"

\author{
Assoc. Prof. Dr. Toni Traykov \\ Assoc. Prof. Dr. Kliment Naydenov \\ Sofia University “St. Kliment Ohridski”, Bulgaria
}

\begin{abstract}
Negative trends in the development of the rural population in Bulgaria are associated with accelerated decline in its numbers, its uneven spatial distribution and permanent alterations in its structural characteristics. As a result of the strongly marked aging of the rural population remains almost ubiquitous downsizing of reproductive and working age. This is a significant social problem, especially in remote and small population settlements. As negative from the perspective of demographic and economic development of rural communities in the country can also be determined and changes in sex ratio in some age groups, family, marriage, education and qualification structure of the population.
\end{abstract}

Keywords: demographic crisis, the demographic transition, rural population, villages, rural settlements

\section{INTRODUCTION}

In the late 20th century the Republic of Bulgaria has entered the fifth stage of the demographic development. The mortality rate exceeds the birth rate and leads to depopulation.[1] Compared to the general negative demographic trends in Bulgaria changes in number and structure of the population in the villages seems to be catastrophic and irreversible. Over a long period of time, the rural population has been crucial to the overall development of the country. Over a long period of time, the rural population has been of a crucial importance for the overall development of the country. Maintaining the agricultural character in the economic development of Bulgaria from the Liberation to the first years after World War II was the dominant factor for the importance of the rural population in general demographic development. During the same period, the rapid growth of its number continued until the mid-20th century. The low degree of urbanization, slow development and growth of cities cause minimal decrease its share in the period from $81.2 \%$ to $75.3 \%$. Crucial for increasing the number of rural population in Bulgaria until the mid-20th century is the preservation of high natural growth. Influence in this direction has its low migration mobility during World War II. The reduction of the rural population that began after the census in 1946 is earlier expression of negative demographic trends. The overall reduction of the country's population began after the census in 1985. Contribution to the depopulation of the rural villages, located near the state border of Bulgaria was the introduction of extremely strict arrangement for the movement of the population, for construction work and other activities in the 30-km border zone with Turkey, Greece and the former Yugoslavia. These limitations, together with the lack of transport provision, moreover isolated and depopulated outlying rural areas in the hinterland. The actual growth of the rural population in Bulgaria after the 
census in 1946 is negative. Most expressive reduction of its number is in the periods 1966 - 1975, 1986-1992 and 2002-2011. As a result of negative changes in natural and migration movement the average annual reduction of rural population close to $2 \%$ during those periods. Rural population for the period until 1990, and in particular for the years between 1980 and 1985 decreased by about $1.6 \%$ per annum (as opposed to urban, which increased by $1.3 \%$ per year). These trends began in the 60 s and early $70 \mathrm{~s}$, when a number of industries requiring a large workforce reduced volumes as a result of demographic processes in Bulgarian villages. The basis of these processes is aging.[3] Mass migration of young people to the cities created conditions for the rapid decrease in fertility in the rural population, and later to a process of intensive aging. Socio-economic changes during the 90s reflected mostly of the rural population. The economic crisis accompanying the transition from planned towards a market economy and the slowdown of the reforms in agriculture, created conditions for the continuation and deepening negative tendencies in its demographic development.

Substandard living conditions due to the economic crisis during the transitional period in the country reflected on the reproductive attitudes and behavior of the population. The number of births dropped from 105 thousand in 1990 to 72 thousand in 1996. As a result, the birth rate in 1996 reached 8,6\% (9,0\% in cities and 8, $0 \%$ in villages)[4]. As a result of the negative natural growth rate and the number of rural population dropped from 1992 to 2011 with about 757 thousand people. Main factor for this decrease is the negative natural growth, as a result of very low birth rates and higher mortality rate in villages. Stronger aging of the rural population continues to determine differences in multiples of reproduction of the population in the towns and villages. In Bulgaria this trend is observed of certain increase in the birth rate after the end of the last century that can be considered as a result of the partial economic stabilization and its impact on the reproductive behavior of the population. Unfortunately, the display of this trend in the villages is too weak. Aging of the rural population and significantly fewer birth contingents were reason for the minimum increase in the birth rate in the villages. In 2007 in cities the birth rate reached 10,4 \%o, and in villages - only 8,5\%o. In 2011 there is decrease of difference of birth, respectively 10,0\% in urban and 8,7\% in the rural population. As a whole at the current stage the rural population in Bulgaria is still with higher fertility associated with slowly changing reproductive attitudes, particularly in some ethnic and religious groups and communities. In 2011 total fertility rate in rural areas is 1.74 and 1.43 in the cities. Much higher differences are in the rates of mortality due to differences in the degree of aging. In 2011 current statistics reported the mortality in the villages is $21,4 \%$ and $12,2 \%$ in cities. During the same year the reduction of the population in Bulgaria, measured by the rate of population growth are $-5,1 \%$. Urban population is its value $-2,2 \%$, and for agriculture - $(-12,7 \%)$. This means that the reduction of the country's population in practice is a result of natural growth mainly due to negative demographic trends in the villages.

In Bulgaria the natural movement of the rural population may indicate as unfavorable moment relatively slow reduction of infant mortality. The infant mortality rate is an important indicator for the overall development of a country and reflects the quality of life of its population. Despite the downward trend in the last and the beginning of this century Bulgaria still has relatively high levels of this important indicator in comparison with other EU countries. This refers to the rural population of the country. In 2011, in Bulgaria the infant mortality in villages is $10,8 \%$, in the cities is $7,7 \%$ and the average value for the country is $8,5 \%$. In Bulgaria the modern demographic situation in the 
villages is a result of the dynamics of the migration process in the second half of $\mathrm{XX}$ century. Strong impact on the migration behavior of the population during this period had socio-economic changes, alteration in the administrative-territorial division of the country, industrialization, infrastructure development and urban policy. Negative impact in this direction had also the processes of consolidation and concentration of territorial units, settlement of numerous rural communities and their integration in local systems and the artificial creation of one of the largest communities in Europe. During the period 1993-2001 more than $70 \%$ were younger age groups who migrated from the countryside to the cities. The third largest in number migration flow in the first decade of the new century is "urban- rural". It reduced to about quarter of the total number of migrants in the country after emigration in the directions ,city-city" and "village-city“. The smallest shares $(8.9 \%)$ have migrated under the "village-village". This migration is a decrease compared to 2001 when it accounted for 12.0 percent of all migrations in the country. During 2002-2011 unfavorable direction had and in the changes in the external migration. Based on NSI data here are settled only 18,688 people, of which only 2.7 thousand have chosen as a place to live villages in different parts of the country. Minimum is the number of immigrants in Bulgaria come from other countries and prefer to settle in some villages in in the country. Data analysis confirms the conclusion that currently the villages in Bulgaria are not preferred place to live and personal realization. Statistics show quite a small number of supporters of the environmental benefits and romance of rural life. Migrations by representatives of some ethnic groups are exceptions. In 2003 National Report on Human Development shows that the Roma migrate mostly in villages, the Turks - in small towns and Bulgarians in major regional centers (Sofia, Varna, Burgas, Ruse, etc.). In some regions of the country that leads to the displacement of the adult population of $t$ Bulgarian ethnic community in the villages by the Roma ethnic group.

Last census data show that by February 1, 2011 in the villages of Bulgaria live 2026 thousand people, or 27.5 percent of the total population. In comparison with 1946 the number of the rural population has declined more than 2.5 times. At the same time dramatically decreased and its share - three-quarters of a quarter. It can be said that now the relationship between urban and rural population in the country is in reverse dependency compared with the census in 1946. NSI data shows that depopulation continues. Now less than 2 million people lives in the villages.

Quantitative changes related to the number of rural population in recent decades are accompanied by changes in its territorial division. During the period 2002-2011, the rural population has decreased in absolute numbers in all areas of the country except the Sofia District (capital). Growth of its rural population of about 5000 people is due to the proximity of villages to the largest administrative, economic, cultural and educational center of Bulgaria. In 2001 and 2011, data show except an absolute reduction, a decrease in the proportion of rural population in 12 of the 28 districts of the country. More significant reduction (3 and more percentage points) is reported in the regions of Veliko Tarnovo, Vidin, Vratsa, Pazardjik and Rousse. In 6 districts (Dobrich, Lovech, Silistra, Stara Zagora, Targovishte, and Haskovo) is keeping the relative proportion, and in other 12 is registered growth. More significant (with 3 and more percentage points) increase is in share of the rural population in the districts of Blagoevgrad, Burgas, Varna, Kardzhali, Plovdiv, Sliven and Sofia (capital).Changes of districts match to the regional characteristics of reproduction, migration movements and factors that determine them. Leading importance have reproductive attitudes and behavior of the population related to his age and ethno- confessional composition and migration to settlements located close 
to the best developing cities of the country - Sofia, Plovdiv, Varna, Burgas and others. Plovdiv District have the highest share of rural population in the country $-8.7 \%$, followed by Blagoevgrad (6.5\%), Burgas (5.2\%) and Pazardzhik (5.1\%). A quarter of the rural population in Bulgaria falls of those four districts. Currently, only in three districts (Kardzhali, Razgrad and Silistra) the rural population has a larger number of the urban population. This trend is best expressed in Kardzhali district, where its share is $58.5 \%$ from the total population, for comparison, in 2001 the same three areas have rural population above 50\% and the highest was the value in Kardzhali district (60.1\%).

The dynamics of socio-economic and demographic processes lead to significant changes in the quantitative and qualitative characteristics of rural settlements, as part of the overall settlement system. In the second half of the last century the number of rural villages is constantly decreasing. The census in 1946 all rural settlements (villages, hamlets, huts, station, industrial and mining) numbered a total of 5927. Almost four decades later, in 1982 their number is 5102. Apart from the changes of an administrative nature, contribute to the reduction of rural settlements there and deletion of villages remained without population. During period of socio-political and economic changes elimination of rural settlements from the list of settlements affected mostly scattered settlements (huts and hamlets). Encountered in other socio-economic conditions, scattered settlements remain without population because of the disability towards the modern life and business. At the same time remaining on the list of settlements rural settlements continuously reduce the number of its population.

Data from the 2011 census indicate the existence of a large number of villages with a minimum population. In 20111627 villages (32.2\%) are with population from 1 to 99 inhabitants from a total of 5047 villages. Their population is about 59 thousand people, or just $0.8 \%$ of the population. The process of reduction continues at an accelerated course. According to data from the current statistics in 2012 from all 5278 villages in the country 172 are without population. The largest numbers of villages with no population in the district are Gabrovo, Veliko Tarnovo and Kardzhali. Impressive is the continuing increase in settlements with minimum population. In Bulgaria 1130 of all villages are with population from 1 to 49 people. The most affected by depopulation settlements and municipalities are located in the Eastern Rhodopes.[2] During 1992-2002 in the municipalities of Madjarovo, Krumovgrad, Kirkovo, Banite and other the population decline with about $25 \%$. As a result of the continued migration of population of the Turkish ethnic groups or emigration to other parts of the country caused by the closure of production facilities, the lack of alternative employment, favorable conditions for the development of agriculture, the problems with tobacco and etc. the population in the settlements decreased. Preserved traditions in the reproductive behavior of the local population are powerless to compensate for the loss of migration. Other parts of the country with a high degree of depopulation are border and mountain areas (Boynitsa, Kula, Makresh, Chuprene, Treklyano, Malko Tarnovo, Boliarovo, Elena etc.). Settlements within them quickly reduce the population as a result of the negative natural growth due to the high degree of aging and extremely limited fertile contingents. In perspective the adverse trends in the dynamics of the rural population is associated primarily with the preservation of negative natural growth and negative changes in its demographic composition (gender, age and family and marriage). Sex structure of the population, including the rural population is mostly determined by the dynamics of fertility and mortality, and migration intensity. At the beginning of the new century the difference increases for 1000 men fall 1051 women compared to 2011 the difference 
increases to 1000:1054. Key factors for the gender imbalance for the country are the low birth rate, the higher male mortality and increased life expectancy among women. In the process of migrating men participate more often than women. A slight predominance of the female population in the villages to the beginning of the new century can be explained by the process started in the 70s and 80s of last century, the process of moving part of the female working age population from rural to urban.

A prerequisite for this is the development of a number of economic sectors and activities, expanding employment opportunities for women in cities. Unlike the census 2001 when women are with 204 thousand more than men, the last census in 2011 this difference is 191 thousand people. The decrease is associated with the observed over the past decade upward trend in the number of women emigrating from the country. Nevertheless, women retain a large share of it due to their pronounced dominance in the population over 50 years. In urban and rural population there is a difference in the presentation of both sexes. In the villages they are less pronounced. In the villages men under 60 years are more than women, they begin to dominate at the age group (60-64). This feature is due to differences in age-specific death rates, and the continuing emigration of women in working age from rural to urban. Although less pronounced differences in the proportions of men and women of reproductive age in the rural population are also important for the process of reproduction. Their influence is accelerating as a result of constantly declining fertility contingents.

Changes in the age structure of the rural population in Bulgaria are directly related to the strong negative trends in its reproduction. The processes of industrialization and urbanization, administrative and territorial changes and related migration from the countryside to the cities began in the $50 \mathrm{~s}$ and $60 \mathrm{~s}$ of the 20th century this reflect substantial adverse effects on the age structure of the rural population. In the early $80 \mathrm{~s}$ about $60 \%$ of the population aged 65 and over lived in villages. Although with lower rates of young population migration to cities in the last two decades, continue to define the aging of the rural population. As a result, the share of the population in aged 65 and over increased from 24.89 percent in 2001 to $25.5 \%$ in 2011 . To compare the relative increase in the same age group in urban population is from $13.1 \%$ to $15.8 \%$. Aging is particularly pronounced among women in the villages. The Census 2011 shows that one-third of the female population in villages is aged 65 and older. At the same time marked and significant differences in the rates of decrease of population in working age. For the years between the last two censuses reduction in the proportion of population is larger in urban population (from 17.1 to $14.1 \%$ ) than in rural (from 15.7 to $14.0 \%$ ). In this case, the lower rates of decrease in the rural population responses for significantly earlier began the process of aging, lead to exhaustion of the demographic potential in the villages. Overall reduction of the rural population includes the reduction of the number of average age groups (30-59 years). Although to a lesser extent, they also relate to the process of reproduction, while they account for the role of maintaining the villages as centers of a certain type of business. During 2002-2011 proportion of the population of these age groups in villages decreased from 894.9 thousand to 758.6 thousand people. The rate of reduction of this most active part of the rural population depends largely on the continuation of economic and urban functions of villages in various parts of the country. In 2011 Bulgarian Academy of Science shows research that the best prospects for this are villages in the districts of Blagoevgrad, Burgas, Varna, Dobrich, Kardzhali, Pernik, Razgrad, Smolyan and Sofia (capital). These estimates relate to the preservation of a large number of working-age population parades proximity to major business and 
administrative centers, or maintained for decades a higher birth rate than the national average, providing more new additions to this age group.

Like the gender-age structure, family-marital structure of the population also influences its natural reproduction. This effect is most pronounced in terms of birth rate, since the majority of births in the country are still families with legal marriage. On the other hand family-marital structure itself is formed by the action of a number of factors such as gender and age structure of the population, its ethnic and religious contribution social status, etc. Existing features in the demographic development of urban and rural population in Bulgaria determine the existence of differences in their family and marital structures. According to the census from 2011 the proportion of unmarried rural population is $36.7 \%$, while the unmarried urban population it is $40.8 \%$. This difference is due to more pronounced aging of the rural population, which determines the weaker performance to singles category (unmarried). The aging process is a factor for the larger share of widows the in villages $(13.8 \%)$ compared to urban areas $(8.9 \%)$. The most pronounced difference is between the shares to widowed women in rural areas $(21.6 \%)$ and urban (14.2\%). The age structure of the rural population and its lifestyle are the reason for the much smaller number of divorced people in the villages. The census from 2011 shows indicates that the number of the divorced couples in the villages is about 4 times less than those in cities. The share of divorced people in rural areas is $4.1 \%$ compared to those in urban areas- $6.5 \%$. Divorced women in rural areas are $3.4 \%$ of the total number of women, in the cities their share is more than twice as high $(7.4 \%)$. The difference is less pronounced in men $-4.7 \%$ in rural areas and $5.4 \%$ in urban areas.

In the rural population divorced men have the highest share in the age group 40-59 years. Compared with the research from the census in 2001, in 2011 in the villages there is an increase in the proportion of unmarried, widowers, widows and divorcees, and decrease in the married one. This match largely with the general trend for the population in the country as the differences are mainly in the rate of increase (decrease) The process of aging, conditions and way of life in village determine the slower increase in the proportion of divorced people in the rural population. Currently in the villages in Bulgaria is increasing the number of cohabitation without formally marriage. In 2011, research shows that this category includes 172.8 thousand people in villages and 406.7 people in cities. The rural population growth in cohabitation without formal marriage is more pronounced among the Roma and significantly less among the representatives of Bulgarian and Turkish ethnicity. In terms of age characteristics, data shows that people of age between 20 and 39 years account $65 \%$ of cases of marital cohabitation in the villages. Changes in family and marriage structure of the rural population lead to series of problems, mainly related to the large number of single adults in the villages. Because of theirs advanced age, they need specialized medical care and social support, which in most cases are missing, or are not to the required level. Social significance has the problem of a large number of divorced men from age groups in terms of limited social contacts in the villages have little chance of remarriage or cohabitation. The educational structure of the population is connected to the socio-economic structures, but also relevant to the mode of reproduction and its related indicator. It has been shown that increasing the level of education affect reproductive attitudes and behavior of people. Usually the birth rates and fertility are inversely related to the level of education. Distribution of the population of 7 years and over by level of education shows considerable differences in urban and rural population in Bulgaria. Against a general increase in the educational level in the country as a whole, the rural population is observed features as a result of changes 
in the age structure and the ongoing and now migrations from the countryside to the cities. Regionally, there is a definite impact and spread of some ethno-confessional groups and communities of the rural population, which are characterized by their lower educational level. Among them are representatives of the Roma and Turkish ethnic groups. Typical examples of that are the municipalities of Kardzhali, Silistra, Razgrad and others districts of the country. Monitoring the process of raising the level of education of the population in Bulgaria in the 20th century and the beginning of the present century has less expression in the villages. Researches from the last two censuses show that in village still prevalent people with basic education, in 2011 their share is $37.8 \%$ of the population of 7 years and over. Second after them are the people with secondary education (33.8\%). For comparison, the average value of these two categories of the population in the country is respectively $23.1 \%$ and $43.4 \%$. Even more pronounced difference in terms of graduates. In 2011 their share in the country is $19.6 \%$, while from the rural population it is only $5.8 \%$.

In addition to the aging process differences are predetermined and from the migrations of young people with higher education to the cities where they can find better conditions for personal and professional development. Maintaining a relatively low share of population with secondary and higher education in villages in perspective will cause a growing lack of qualified specialists. Such shortages now exist in the areas of health, social care and support for elderly residents of the villages. There are also problems with the selection of teachers willing to work in schools in villages that still have children for formation of educational classes. The situation is identical for finding a sufficient number of specialists in activities related to agriculture and others. Disturbing trend for the last two decades is the increasing number of people excluded from the education system, as well as those who have never attended school. It is significant that in 2011 the number of people never attended school in rural areas is more than half of the total for the country. The increase in the number of this category in the country including the rural population was primarily associated with areas where there is a compact representation to Roma and Turkish ethnic groups. As an example may be mentioned municipalities in the districts of Sliven, Kardzhali, Razgrad and Silistra. For the last three of them to a person low enrollment of adolescents in education, a high proportion of ethnic population groups and rural population of over $50 \%$. In the villages the literacy rate of 9 years and over is unfavorable. Last census data show 57.6 thousand in the villages are illiterate in comparison to 55.2 thousand in cities. The lack of any education in some of the rising generation further deepen problems and an obstacle to of program implementation to reduce the negative trends related to rural villages in Bulgaria. Changes in the values of the basic demographic indicators between the last two censuses give reason to determine the existence of a weakening of negative trends in population in Bulgaria. The slowdown in the rate of decrease of the population is an evidence for this process also some increases in the birth rate and fertility of birth contingents, reducing child mortality, extension of life expectancy, reducing international migration and others. The above changes are related mainly to the average value of the population of Bulgaria in a much lesser extent on the demographic situation in villages. Deepening of the existing problems for decades continuous reducing number of the rural population is determined by regressive changes in its structural characteristics, directly related to the highly violations regime of reproduction.

In the current stage of this demographic situation in the villages of Bulgaria is difficult to talk about demographic development. Against the continued reduction in the average size 
and number of rural settlements in the country as the most optimistic scenario for their future is to achieve more moderate growth of depopulation in rural areas. Otherwise, the progressive depopulation of the countryside can lead to irreversible changes and effects of social, economic and environmental nature. These may be difficulties in the normal maintenance of farmland and forests, increasing the uncultivated areas, the reduction of agricultural production and produced in our crop and livestock production and others. All this will lead to an increase in agricultural prices, the intensification of unfavorable natural phenomena such as landslides, forest fires and others. Mitigating these extremely unfavorable trends requires the fulfillment of any programs related to the demographic future of the villages in Bulgaria to conform to the following basic requirements. The first one requires the formulation of clear criteria for defining rural areas. By 2011 in Bulgaria and in other countries in EU, rural areas were selected on the basis of a single indicator, namely the population of the main settlement does not exceed 30 thousand residents. A new more complex methodology is introduced on the same year which requires the digitization of the country and defines the geographical population density of territorial cells. Difficulties in implementing the new method could lead to a delay or return of the administrative approach in determining the rural areas. Another important requirement is the need for continuous improvement in the work of institutions involved in completing the programs for rural development, as well as control measures and the decentralization of their activities and management. The implementation of these measures requires optimum use of the existing rural local institutional capacity and providing more power, resources and responsibilities under the regional and municipal governments. This means active participation of the local population in defining measures and decisions on their implementation. In this direction active role can have non-governmental organizations to coordinate their actions with the interests of the rural population.

\section{REFERENCES}

[1] Minkov, M. Demography, Bulgaria, Sofia, 1999.

[2] Mladenov, Ch., E. Dimitrov. Depopulation - a major geographical problem of the demographic crisis in Bulgaria. Bulgaria, Sofia, 2005.

[3] Naydenov, Kl. Demographic policy of the Republic of Bulgaria - a factor for sustainable development. Dissertation for awarding the educational and scientific degree "doctor", Bulgaria, Sofia, 2012.

[4] Traykov, T. Geographical aspects of the demographic crisis in Bulgaria. Bulgaria, Sofia, 1998. 